\title{
Intonation and polar questions in Greek revisited
}

\author{
Antonis Botinis ${ }^{1}$, Anthi Chaida ${ }^{1,2}$, Olga Nikolaenkova ${ }^{3}$, Elina \\ Nirgianaki ${ }^{1,2}$ \\ ${ }^{1}$ Lab of Phonetics \& Computational Linguistics, University of Athens, Greece \\ ${ }^{2}$ Faculty of Primary Education, University of Athens, Greece \\ ${ }^{3}$ Department of General Linguistics, Saint Petersburg State University, Russia \\ https://doi.org/10.36505/ExLing-2016/07/0007/000266
}

\begin{abstract}
This is a study of intonation and polar questions in Greek. The results indicate that there is a rising-falling tonal structure at the right edge of polar questions. However, the alignment of both tonal rising and tonal peak depend on the position of focus as well as lexical stress. Thus, in the context of initial and medial focus productions, the tonal rising is aligned with the onset of the final stressed syllable whereas, in the context of final focus production, the tonal rising is aligned with the onset of the last syllable regardless of the position of lexical stress. On the other hand, the tonal peak is aligned with the post-stressed syllable in the context of initial and medial focus productions whereas, in the context of final focus production, the tonal peak is aligned with the nucleus of the last syllable. However, the earlier the lexical stress production, the earlier the tonal rising as well as the tonal peak in all focus contexts.

Key words: polar questions, intonation, Greek, focus, tonal associations
\end{abstract}

\section{Introduction}

Statements and polar questions in Greek, much like in e.g. Italian and Russian, hardly have any other correlates except for intonation. Lexical stress production in statements may be associated with a tonal rise in prefocus position whereas, in focus position, a local tonal expansion is followed by a postfocus tonal flattening (e.g. Botinis 1989). In polar questions, on the other hand, there is no tonal expansion of focus asignment but a rise-falling shape at the right edge (e.g. Chaida 2010).

In a recent study (Chaida, Sotiriou, Kontostavlaki 2016, this volume), the rising-falling tonal shape of polar questions at the right edge is fairly evident, but a tonal expansion of focus application is also evident, leading us to the question: what are the basic characteristics of polar question intonation in Greek? In this study, we have developed a new question-question methodology, according to which a first wh-question elicits a polar (yes-no) question. We think that this methodology is straightforward and may be applied to other languages in principle, especially to languages with no other morphological and/or syntactic means to produce polar questions but intonation.

ExLing 2016: Proceedings of $7^{\text {th }}$ Tutorial and Research Workshop on Experimental Linguistics, 27 June - 2 July 2016, Saint Petersburg, Russia 


\section{Experimental methodology}

The speech material of the present study consists of two serries of a question-question methodological paradigm sequence. The first question is an elicitation Wh-question, in order to assign a specific focus at the second question, i.e. the target question, which is a polar question with variable final lexical stress assignment at one of last three syllables (Table 1). In the first series, the target question is a full question, whereas, in the second series, the target question is an eliptical one, corresponding to the final prosodic word of full question (Figures 1-4).

Five female speakers, 20-40 years old, with standard Athenian pronunciation, produced the speech material at a normal tempo in a sound-treated room at Athens University Phonetics Laboratory. The speakers red the speech material from a piece of paper, first the elicitation question followed by the target question.

The speech material analysis was carried out with Praat, with several annotation tiers. In this report, we have concentrated on one tier, i.e. the stressed vs. unstressed prosodic distinction, and the speech material has been normalized with Prosody Pro tool (Xu 2013).

Table 1. Elicitation questions (left) and target questions (right) with variable final lexical stress as well as neutral and variable focus assignments (bold letters).

\begin{tabular}{|c|c|c|c|}
\hline 1.2 & $\begin{array}{l}\text { [pça ðu'levi sti 'madova]? } \\
\text { 'Who works in Mantova'? } \\
\text { [pça ðu'levi sto mi'lano]? } \\
\text { 'Who works in Milano'? } \\
\text { [pça ðu'levi sto bana'ma]? } \\
\text { 'Who works in Panama'? }\end{array}$ & $\begin{array}{l}1.1 \\
1.2 \\
1.3\end{array}$ & $\begin{array}{l}\text { [i 'nana ðu'levi sti 'madova]? } \\
\text { 'Nana works in Mantova'? } \\
\text { [i 'nana ðu'levi sto mi'lano]? } \\
\text { 'Nana works in Milano'? } \\
\text { [i 'nana ðu'levi sto bana'ma]? } \\
\text { 'Nana works in Panama'? }\end{array}$ \\
\hline 2.3 & $\begin{array}{l}\text { ti 'kani i 'nana sti 'madova? } \\
\text { What does Nana in Mantova? } \\
\text { ti 'kani i 'nana sto mi'lano? } \\
\text { What does Nana in Milano? } \\
\text { ti 'kani i ' nana sto bana' ma? } \\
\text { What does Nana in Panama? }\end{array}$ & $\begin{array}{l}2.1 \\
2.2 \\
2.3\end{array}$ & $\begin{array}{l}\text { [i 'nana ðu'levi sti 'madova]? } \\
\text { Nana works in Mantova? } \\
{[\text { i 'nana ðu'levi sto mi'lano]? }} \\
\text { Nana works in Milano? } \\
\text { [i 'nana ðu'levi sto bana'ma]? } \\
\text { Nana works in Panama? }\end{array}$ \\
\hline 3 & $\begin{array}{l}\text { pu ðu'levi i 'nana? } \\
\text { Where works Nana? }\end{array}$ & $\begin{array}{l}3.1 \\
3.2 \\
3.3\end{array}$ & $\begin{array}{l}{[i \text { 'nana ðu'levi sti 'madova]? }} \\
\text { Nana works in Mantova? } \\
{[i \text { 'nana ðu'levi sto mi'lano]? }} \\
\text { Nana works in Milano? } \\
{[i \text { 'nana ðu'levi sto bana'ma]? }} \\
\text { Nana works in Panama? }\end{array}$ \\
\hline
\end{tabular}




\section{Results and discussion}

In accordance with the aim of the study and the questions addressed in the introduction, the results are presented in Figures 1-4.

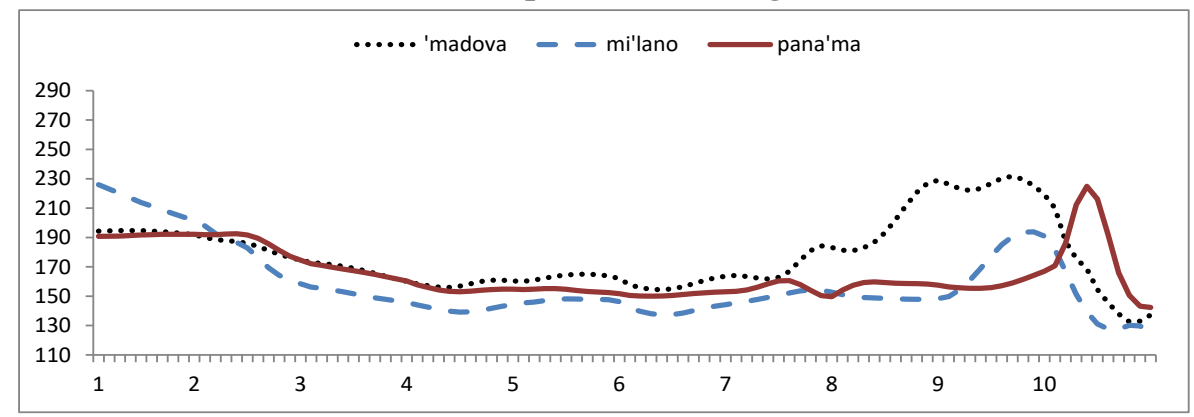

Figure 1. Intonation of polar questions in Greek as a function of initial focus and variable final lexical stress assignments. Numbers on vertical and horizontal axis indicate values in $\mathrm{Hz}$ and syllable boundaries, respectively.

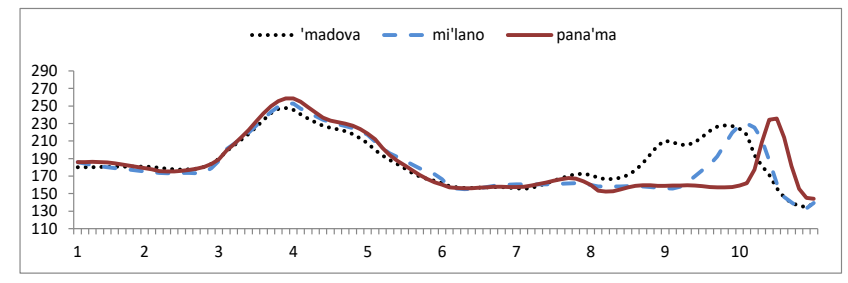

Figure 2. Intonation of polar questions in Greek as a function of medial focus and variable final lexical stress assignments. Numbers on vertical and horizontal axis indicate values in $\mathrm{Hz}$ and syllable boundaries, respectively.

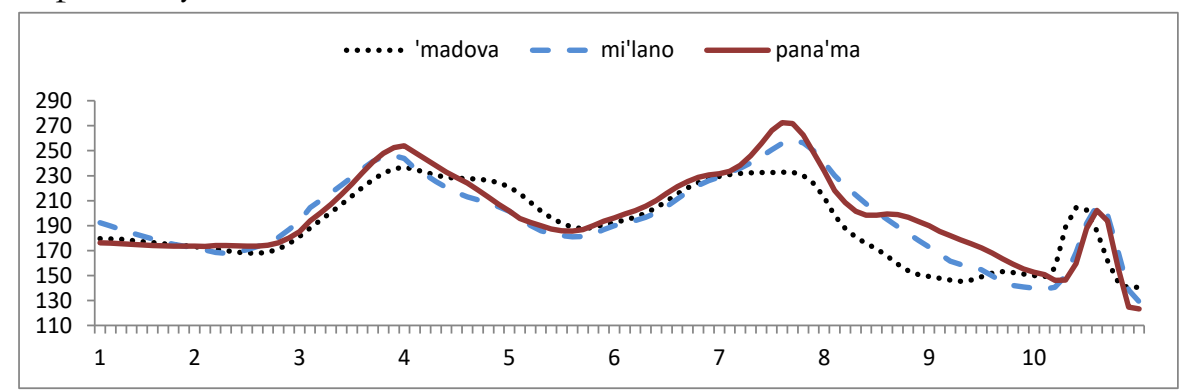

Figure 3. Intonation of polar questions in Greek as a function of final focus and variable final lexical stress assignments. Numbers on vertical and horizontal axis indicate values in $\mathrm{Hz}$ and syllable boundaries, respectively. 


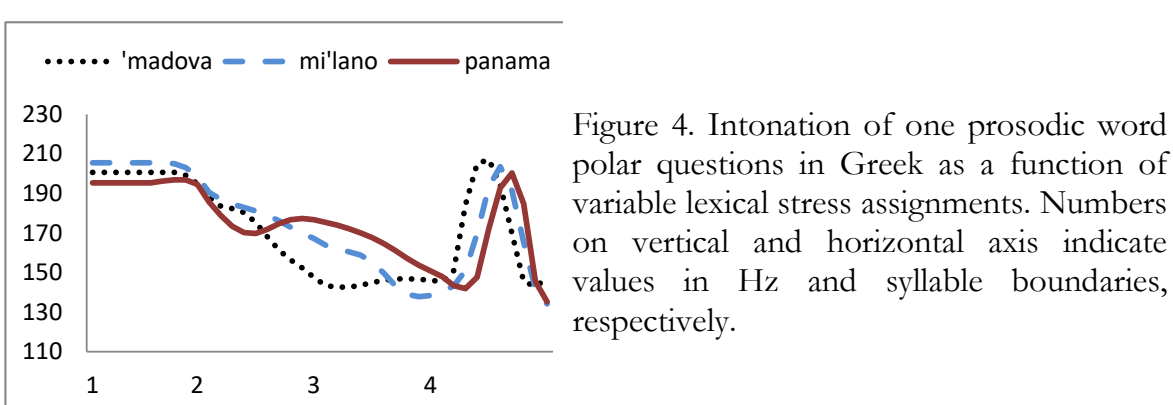

Initial focus productions (Figure 1) show only one right edge tonal peak, which is aligned with the nucleus of the last lexical stress whereas the tonal rise is aligned with the onset of respective syllables. Medial focus productions (Figure 2), in addition to a tonal peak at the right edge, show another peak aligned with the post-stressed syllable of the first word. Final focus productions (Figure 3), show three tonal peaks, the first two aligned with the post-stressed syllables of respective words whereas the third one is aligned with the last syllable of the sentence. However, the earlier the lexical stress the earlier the alignments of both tonal rise and tonal peak, which is also evident in one prosodic word polar questions (Figure 4).

The rise-fall tonal production at the right edge of polar questions has also been reported in other languages (Grice, Ladd, Arvaniti, 2000) and Brazilian Portuguese (Castelo, Frota, forthc.). These studies are in the framework of Autosegmental-Metrical phonology and argue for a sequence of three tones, i.e. LHL, with reference to the rising-falling tonal production at the right edge of polar questions. However, in accordance with our results, this is too broad an approach and further research of polar questions and sentence types in general is in place.

\section{Acknowledgements}

Thanks to Athens University Special Research Account for economic support.

\section{References}

Botinis, A. 1989. Stress and Prosodic Structure in Greek. Lund University Press.

Castelo, J., Frota, S. Forthc. The yes-no question contour in Brazilian Portuguese.

Chaida, A. 2010. Production and Perception of Intonation and Sentence Types in Greek. PhD Thesis, University of Athens.

Chaida, A., Sotiriou, A., Kontostavlaki, A. 2016. Intonation and polar questions in Greek. (this volume).

Grice, M, Ladd, R., Arvaniti, A. 2000. On the place of phrase accents in intonational phonology. Phonology 17, 143-185.

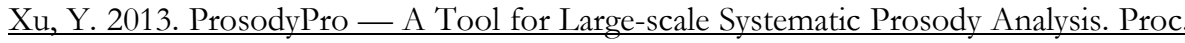
TRASP 2013, 7-10. Aix-en-Provence, France. 